points, and on the whole the inclusion of this material enhances the value of the volumos. With such an extensive field to cover, and with so many papers contributod, it is a commendable feature of the publication that all contributions, apart from the invited papers, are limited to about two thousand words.

This was the ninth of a series of international conferences organized since 1947 by the Cosmic Ray Commission of the International Union of Pure and Applied Physics and the first of the series to be held in the United Kingdom. In his preface to the volumes, Professor J. G. Wilson, chairman of the Organizing Committee, calls attention to this fact and rightly goes on to comment on how appropriate it was that the conference should meet at Imperial College in the month which marked the retirement of one of the great figures of the cosmic ray world, Prof. P. M. S. Blackett.

All too often a just criticism of the proceedings of scientific conferences is that their publication is delayed many months, sometimes even years, after tho conclusion of the meeting and it is not unknown for papers presented at conferences to be outdated long before the proceedings appear. In the present case the editors and publishors are to be congratulated on achieving early publication of such a substantial body of material. The volumes are excellently produced by a photo-offset process and the price is reasonable.

W. J. G. Beynon

\section{ORBIT THEORY}

\section{Orbital Hodograph Analysis}

By Samuel P. Altman. (American Astronautical Society Science and Technology Series, Vol. 3.) Pp. 134. (Baltimore, Md.: American Astronautical Society, 1965. Distributed by Western Periodicals Co., North Hollywood, California.) \$11.25.

Classical theories of celestial mechanies dopend on expressing the properties of orbits in terms of orbital elomonts, for example, semi-major axis, eceentricity, etc., and then investigating the changes in the elements. An alternative approach, which is the subject of this book, is to make use of the hodograph, that is, to focus attention on the velocity or acceleration vector of the body in orbit. Chapter 1 is introductory and shows that the volocity hodograph of an ellipse, parabola or hyperbola is a circle, the origin being inside the circle if the orbit is an ellipse, on the circle for a parabola, and outside for a hyperbola: the hodograph thus allows changes from elliptic to hyperbolic orbits without the discontinuities which bedevil classical analysis. Other forms of hodograph are also definod. Possible analytical transformations are discussed in Chapter 2 and trajectories of ballistic missiles in Chapter 3. Orbital transfer and its optimization aro the subjects of Chapter 4, and Chapter 5 is concerned with orbital rendezvous. Chapter 6, on lunar landing, shows how numerical solution by hodograph methods is just as good as by normal methods, despite the fact that the landing point, with zero velocity, becomes indeterminate in the hodograph formulation. A final chapter offers suggestions on the future uses of hodograph methods, including optimization problems and the $n$-body problem.

Dr. Altman has provided a useful introduction to a theoretical method which may well prove important in the future, and it is a pity that the book has several annoying faults. 'To begin with, symbols are usually left undefined in the main text, and the reader has to keep on referring to the list of symbols at the end of the chapter, where the definitions are not always immediately comprehensible. The book appears to be printed photographically from a typescript: unfortunately the print is very faint on many pages and part of pago 69 was quite invisible in the review copy. Also on some pages the print extends to within $5 \mathrm{~mm}$ of the stitching on the spine and is unreadable unless the book is almost torn apart. Finally, the standard reviewer's complaint that the book is too expensive really does seem justified when it is so short and so poorly printed.

D. G. KING-HeLE

\section{CARBONYL CHEMISTRY}

\section{The Chemistry of the Carbonyl Group}

Edited by Saul Patai. (The Chemistry of Functional Groups.) Pp. xii + 1027. (London and New York: Interscienco Publishers, a Division of John Wiley and Sons, 1966.) 220s.

THIs is the second volume to appear in the series of large monographs on individual functional groups edited by Prof. Patai, and it follows very closely the pattern of its predecessor on the alkenes. The resemblance extends even to the fact that a salient chapter-in this caso the one on equilibrium additions to carbonyl groups-is missing because the manuscript did not materialize on time.

There is no question but that this is a useful compilation, its seventeen chapters containing an abundance of information and a wealth of refercnces. One does, however, wonder a little at the balance of space allocated to various topics: whether, for instance, the photochemistry of aldehydes and ketones merits the longest chapter in the book, and whether in the chapter on chemical and physical methods of analysis the former should receive as much emphasis as the latter. Multiplo authorship makes it vory difficult to maintain uniform standards, with the result that some chapters tend to become catalogucs while others present a reasoned, and even elegant, review of their topic. Examples of the latter are the chapter on general and theoretical aspects of the carbonyl group, and the one on the basicity of carbonyl compounds, though it is only fair to say that their rather general subject matter assists in achieving a more spacious view.

The book includes extensive surveys of methods by which carbonyl groups may bo formed as well as the reactions that they undergo, but there is no formal treatment of the effect of carbonyl on adjacent groups. This is not unreasonable oxcept perhaps as it effects $\alpha$-hydrogen, though there is some discussion of aldol and kindred reactions in Chapter 12.

'The book's production standards are relatively mediocre and, large though it is, its price puts it beyond the reach of all but institutional buyers. PETER Sykes

\section{ORGANIC REACTIONS}

\section{The Investigation of Organic Reactions}

By Ross Stewart. (Prentice-Hall Foundations of Modern Organic Chemistry Series.) Pp. xii + 125. (Englewood Cliffs, N.J., and London: Prentice-Hall Inc., 1966.) 20 s. paper; $44 s$. cloth.

Reaction Mechanisms in Organic Chemistry

By Blanca Tchoubar. Pp. xiv + 197. (London: Iliffe Books, Ltd. ; New York: Amorican Elsevier Publishing Company, Inc., 1966.) 45s. net.

A sound appreciation of the mechanisms of organic chemical reactions requires a reasonable background knowledge of how these mechanisms are determined and this The Investigation of Organic Reactions provides in a clear and concise manner. A detailed and satisfying survey of equilibria, reaction intermediates, transition states, reaction paths, and catalysis is given in the course of five chapters to each of which there are appended soms half a dozen problems. The treatment is stimulating and the book can confidently be recommended both to undergraduates approaching the subject for the first timo and to more experienced chemists who wish to renew their acquaintance with this field. 